\title{
Top Manager Orientation, Management Accounting Systems and Strategy Implementation: Evidence from the Sri Lankan Manufacturing Sector
}

\author{
Dinushi Wijesinghe and Dileepa Samudrage
}

\begin{abstract}
This paper examines how technically oriented top managers use Management Accounting Systems (MASs) for organizational strategy implementation in the Sri Lankan manufacturing sector. Based on the Upper Echelon Theory (UET), the researchers argue that technically oriented top managers use MASs more interactively than diagnostically and prefer the use of innovative to traditional MAS information. Further, the researchers argue that technically oriented top managers support the implementation of prospector strategy as a result of their innovativeness. In order to achieve the objectives of the study a quantitative based approach was adopted. The hypotheses were developed and tested in a survey among the technically oriented top managers in the manufacturing sector in Sri Lanka. The researchers conducted a few in-depth interviews as well. The findings of the study confirmed that the technically oriented top managers prefer the interactive style in the use of MASs and also prefer to use innovative MAS information. The results also confirmed that technically oriented top managers prefer to adopt the prospector strategy. Further, the findings confirmed that the interactive style of using MASs and innovative MAS information strongly supports the adoption of prospector strategy. The findings confirmed the applicability of UET in the Sri Lankan manufacturing sector. The findings will also aid business organizations in preparing MAS information to complement prospector strategy implementation. The paper contributes to the existing literature on UET and the role of MASs in supporting strategy implementation particularly in a South Asian, Sri Lankan setting.
\end{abstract}

Keywords: developing country, prospector strategy, top manager's use of MASs, Upper Echelon Theory,

Dinushi Wijesinghe is a Lecturer of the Department of Accounting, Faculty of Management Studies and Commerce, University of Sri Jayewardenpura. E-mail dinu@sjp.ac.lk(Corresponding author)

Dileepa N Samudrage, $\boldsymbol{P h D}$ is a Senior Lecturer of the Department of Accounting, Faculty of Management Studies and Commerce, University of Sri Jayewardenepura 


\section{NSBM Journal of Management}

Vol. 1, No. 1, January - June, 2015

\section{Introduction}

The dynamic and evolving nature of today's business organizations has resulted in stiff competition and drives the need for achieving sustainable competitive advantage to obtain better organizational performances. They face the challenge of battling this competition and change, for their survival and growth (Chenhall et al. 2011). These rapid changes have posed a challenge to the entire business models and structures widely and rapidly. The players in the business world as a result face a situation where they have to capitalize on the new opportunities while avoiding the threats. To explore the opportunities and to avoid the threats, the organizations need to be vigilant about decision making on the development and implementation of strategies.

Decision-making with regard to strategy implementation by top managers should be based on various types of relevant information. The use of Management Accounting Systems (MASs) for decision making plays a vital role in generating important and timely information relevant to different units of the organization (Ittner and Larcker 1995).

The main goal of Management Accounting is the coordination and integration of subsidiaries and business units as well as supporting management with relevant information for rational decision making. MASs are used by management as tools of strategy implementation (Simons 1991). However, the use of MASs as a controlling tool for strategy implementation is not an easy task. Top managers responsible for running the organizations often find it difficult to clearly understand organizational strategies and their implementation. Further, they often find it difficult to convert their strategies into operational goals, to achieve them and link those measures with financial performance. Moreover, they are often faced with the challenge of adjusting the strategy implemented according to the changes in the dynamic environment and accordingly the operational goals and performance measures must be adjusted. Therefore, the development and implementation of strategy is very important and top managers have to make these decisions with care. For this purpose, MASs play a key role (Kaplan \& Norton 1996, Simons 1995,Naranjo-Gill \& Hartmann 2006).

Even though MASs facilitate top management with various types of information, all top managers do not process and interpret such information in the same way. Thus, knowing what factors influence these differences in the use of information is important. The Upper Echelon Theory (UET) introduced by Hambrick and Mason (1984) suggests that top managers process and interpret information differently due to various demographic characteristics and values which have an impact on their cognitive base. According to Hambrick\& Masons (1984), 
Top Manager Orientation, Management Accounting Systems and Strategy Implementation: Evidence from the Sri Lankan Manufacturing Sector

the cognitive base includes knowledge of assumptions about future events, knowledge of alternatives, knowledge of consequences attached to alternatives and the values of the decision maker for ordering consequences or alternatives according to preferences. This influences the strategic information they use and the different strategic choices they make.

However, despite the significant literature relevant to strategy implementation in the broader management field, there is a dearth of studies relating to the role of MASs in strategy development and its implementation process (Langfield-Smith 1997) while the findings of some of these studies are inconclusive (Abernethy \& Brownell 1999, Ittener \& Larcker 2001). Particularly studies done on the differences in the use of MASs and strategy implementation relating to UET are scarce and in the Sri Lankan context, the use of MASs and strategy implementation has been rarely studied (Kapu Arachchilage \& Smith 2013). As far as the authors are aware, studies to assess the impact of UET on the use of MAS and strategy implementation in Sri Lanka has never been done.

Strategy implementation has been studied using different strategy typologies (Sumer \& Bayraktar, 2012). Among them, the Miles and Snow strategy typology describes the organization's ways and means of adapting to different environments giving rise to a twofold continuum of the strategy typology defender strategy and prospector strategy where defenders focus on improving the efficiency of their existing operations while prospectors always search for new market opportunities (Miles et al. 1978).

According to UET, the background of top managers can be evaluated through observable demographic characteristics such as age, functional experience (tracks), career experience, education, socio-economic roots, financial position and group characteristics. It is argued that depending on the top manager orientation, their style, type and purpose of using MASs and implementation of strategy will differ (Naranjo-Gill \& Hartmann 2006, 2007, Naranjo-Gil, Maas \& Hartmann 2009). Here, the authors define top manager orientation, based on UET, as professionally (technically) and administratively oriented top managers based on their education and functional experience.

The above background motivated the authors to examine the relationships that exist between top manager orientation and their use of MASs and strategy implementation in Sri Lankan organizations. Accordingly, the research question addressed was: "How do technically oriented top managers use Management Accounting Systems differently for strategy implementation?" Accordingly, three research objectives were formed: first, to identify how technically oriented top managers in Sri Lankan organizations use MASs differently; 


\section{NSBM Journal of Management}

Vol. 1, No. 1, January - June, 2015

second, to identify the relationships between the use of MASs and strategy implementation; and third, to identify the relationship between technically oriented top managers and their strategy implementation.

The remainder of this paper is structured as follows. The next section develops the conceptual framework based on the literature review encompassing the respective hypotheses about the relationships between technically oriented top managers and MASs and strategy implementation. The methodology section describes the design of the study. The data analysis section presents the results of the analysis. The final section presents the discussion, conclusions of the study and directions for future research.

\section{Development of Conceptual Framework}

Prior to developing hypotheses the Upper Echelon Theory is outlined followed by literature on technically oriented top managers' preference for the use of MASs and in relation to the strategy implementation process.

\section{The Upper Echelon Theory (UET)}

UET suggests that the strategic choices made by firms reflect the values and cognitive bases of powerful actors and as a result, the characteristics of top management or the upper echelon of an organization can influence the decisions and practices adopted by the organizations (Hambrick\& Masons 1984, Nishii, Gotte, \& Raver2007, Bantel \& Jackson 1989,Carpenter, Geletkanycz, \&Sanders 2004). Since UET is concerned about the organization's strategic behavior, it is proposed that the managerial orientation should be analyzed at the level of the strategic apex which includes top managers of the organization (Finkelstein \& Hambrick, 1996,Hambrick, 2007, Hartmann, 2005). UET emphasizes that differences between managerial orientations do not merely originate from functional responsibilities but are rooted in the cognitions, values and perceptions that are formed by education and experience (Carpenter et al. 2004,Schäffer \& Steiners, 2004). For example, managers with a dominant orientation in engineering, found it difficult to climb up to the top manager positions while managers with an administrative orientation dominated top managerial positions (Armstrong 1987). Technically oriented engineers were more inclined to manage and control through the professional bureaucracy model where the standardization of skills was the main control mechanism (Abernethy \& Stoelwinder 1990). 
Top Manager Orientation, Management Accounting Systems and Strategy Implementation: Evidence from the Sri Lankan Manufacturing Sector

This study is designed to examine how technically oriented top managers use MASs differently for strategy implementation. The orientation of top managers is therefore one of the key constructs of the study. This was measured based on top manager education and functional experience as stated in UET (Naranjo-Gill \& Hartmann 2006).

\section{Technically Oriented Top Managers and the Use of MASs}

According to UET, based on their education and experience, top managers can be classified into two categories: top managers with a dominant technical (professional) orientation and top managers with a dominant administrative orientation, (Abernethy \& Stoelwinder, 1990, Naranjo-Gil \& Hartmann 2006, 2007, Naranjo-Gil et al.2009, Pavlatos 2012).

Further, Hartmann, (2005) suggested that the preference for accounting-based performance indicators systematically differs from personality-related cognitive characteristics where uncertainty has stronger effects on the perceived appropriateness of accounting performance measures for managers with low tolerance for ambiguity than for managers with high tolerance for ambiguity. Top managers with a dominant technical orientation have a greater understanding of the production process, and are therefore inclined to offer more autonomy and participation to professional colleagues at lower hierarchical levels in establishing working goals (Armstrong 1987, Mintzberg 1990). Abernethy and Vagnoni (2004) showed that professional managers indeed use the accounting system to cope with role conflicts between their medical (technical) and managerial (administrative) roles. Further, these authors have suggested that the top managers with a technical orientation used MASs for communication and dialogue with their professional peers, which is used for interactive controls rather than in a traditional diagnostic cost-oriented way (Mintzberg 1990, Simons 1995, Gaidiene \& Skyrius 2006).

For the purposes of this study the use of MASs is defined in two ways: style of use of MASs and use of innovative MASs. The style of using MASs was measured in terms of interactive use of MASs and diagnostic use of MASs. The use of innovative MASs was measured in terms of the use of innovative MAS information and use of traditional MAS information.

Organizations that use interactive control systems demand attention from all levels of managers, peers and subordinates and encourage organizational attention and learning. As a result, accountability, coordination, motivation and learning are integral to interactive control systems. On the other hand, organizations with diagnostic control systems mainly help managers to track the progress of individuals, departments and production facilities 


\section{NSBM Journal of Management}

Vol. 1, No. 1, January - June, 2015

towards strategically important goals which are needed to monitor the performances against the targets and adjust for any variances (Simons 1991, 2000, Schäffer \& Steiners 2004).

The choice by top managers to use a system interactively or diagnostically represents an element of strategic choice (Simons 1991) and the differences in strategic choices made may be due to the demographic differences of the top managers (Hambrick \& Masons 1984). Professionals are more competent and comfortable with performing the core operating tasks of the organization (Abernethy \& Stoelwinder 1990). This leads technically oriented top managers to use MASs not for mere top-down control but as a device to stimulate accountability, motivation and learning which are elements of interactive controls (Simons 1991, 1995, 2000, Abernethy \& Stoelwinder, 1990, Abernethy \& Lillis 1995, Naranjo - Gill \& Hartmann 2006). Furthermore, top managers with a technical orientation are not confident with, and are not inclined to rely on financial controls when managing the organizations (Song 1982, Finkelstein \& Hambrick 1996), which require less specific knowledge and information of the basic processes, and emphasize the measurement of performance against the set targets (Baysinger \& Hoskisson 1990). This is in line with a more diagnostic use of MASs (Simons 1995, 2000, Abernethy \& Lillis, 1995,Naranjo-Gill \& Hartmann 2006).

This gives rise to the following hypothesis:

H1: With respect to top managers, a high level of technical orientation is (a) positively related to the interactive use of MASs; (b) negatively related to diagnostic use of MASs.

The use of MASs is next studied based on the use of innovative MAS information and use of traditional MAS information. Innovation has become a compulsory element for an organization to sustain and grow in today's competitive business world. As such, to face this stiff competition successfully, the call for innovative performance and controlling measures are ever increasing. For instance, organizations that use more innovative strategies might seek innovative MAS information that would give information not only on financial but also on other non-financial aspects (Kaplan \& Nortan 1996, Chenhall, Kallunki, \& Silvola 2011). Even though modern management accounting techniques are helpful to organizations, the use of such techniques is not common to organizations as much as traditional techniques (Naranjo-Gil et al. 2009).This may in part be explained by individual differences between managers, who ultimately decide about the firms' structural adaption, competitive moves and levels of innovation (Hambrick \& Mason 1984, Finkelstein \& Hambrick 1996). 
The tendency to innovate is positively correlated with the education level and functional experience of top managers (Bantel \& Jackson 1989). According to Hitt and Tyler (1991), strategic decision making is affected by the top managers' academic orientation and further, top managers with a technical orientation are more associated with innovations, inventions and strategic change (Wiersema \& Bantel 1992) and are less focused on achieving controls and efficiencies. Further, top managers with a technical orientation are more familiar with the technical and operational process of the organization and are keen on improving the content of processes (Finkelstein \& Hambrick 1996). Innovativeness in the organization is positively related to the social networking and organic culture of an organization, which includes the elements of willingness to share information and the free flow of ideas and information, joint problem solving, adapting to unanticipated change and promotion of a curiosity and seeking culture, which leads to an interactive mode of using MASs (Chenhall et al. 2011). Maher (2000) has stated that companies developing innovative manufacturing practices also appear to be developing innovative MAS practices. This background thus lets top managers with a technical orientation encourage the introduction of more innovative MASs that better suit the organization's measurement of performance. On the other hand, top managers with a technical orientation are less oriented towards improving the efficiencies of the processes via finance (Song 1982), which are elements of the traditional use of MASs.

This leads to the following hypothesis:

$\mathrm{H} 2$ : With respect to top managers, a high level of technical orientation has a (a) positive influence on the use of innovative MASs; (b) negative influence on the use of traditional MASs.

\section{Use of MASs for Strategy Implementation}

The strategy typology introduced by Miles et al. (1978) presented a theoretical framework that managers and students of management can use to analyze an organization as an integrated and dynamic whole, a model that takes into account the interrelationship among strategy, structure and process.

The Miles and Snow strategy typology conceptualizes that an organization's position as a continuum between prospector and defender types. The defender type organization focuses on improving the efficiency of its existing operations and prospectors always work on finding new market opportunities and thus give emphasis to innovation (Miles et al. 1978, NaranjoGill et al. 2009). 


\section{NSBM Journal of Management}

Vol. 1, No. 1, January - June, 2015

The Miles and Snow's typology further defines prospector strategy as involving dynamism in seeking new market opportunities which they are capable of developing into new products and finding creative responses to suit customer demands requiring flexible strategies (Miles et al.1978, Abernethy \& Lillis 1995, Naranjo-Gil et al. 2009). Manufacturing flexibility refers to the firm's ability to respond to market demands by switching from one product to another through coordinated policies and actions and a willingness or capacity to offer product variations. Further, attempts to maximize differentiation on innovation leads to prospector strategy (Dent 1990, Abernethy \& Lillis 1995).In prospector strategy the relevance of financial measures of manufacturing performance becomes less relevant (Brownell \& Merchant 1990, Hayes 1997). In order to better face challenges through creativity and innovations, new formal control systems must be created which lead to new product line extensions, processes, and markets (Simons 1995, 2000, Ittener \& Larcker 1995). As a result, effective performance measures require a shift from measures which focus on manufacturing efficiencies to measures which encourage inter-functional cooperation and adoption (Macintosh 1985). This will lead to more spontaneous contact and 'integrative liaison devices' (Abernethy \& Lillis 1995, Schäffer \& Steiners2004). These co-ordination mechanisms provide a means of breaking down the functional barriers imposed by mechanistic organizational structures (Galbraith 1973).

The research suggests that more complex and proactive strategies such as prospector strategy require more advanced MASs (Naranjo-Gil et al. 2009). The reason for this is that prospector organizations need to make day-to-day decisions on a wide range of issues and therefore need timelier, less aggregated and broader information (Bouwens \& Abernethy 2000). That is, the prospector firm's emphasis on the importance of customer satisfaction, new product development and flexibility is central to implementing the prospector strategy. The need to measure such aspects of the firm's performances must be integrated into the organization's MAS which increases the demand for more innovative MAS techniques (Kaplan \& Nortan 1996). Accordingly, the prospector strategy will be supported by the interactive use of MASs and of innovative MAS information leading to flexibility and product differentiation (Bouwens \& Abernethy 2000). On the other hand, the prospectors place less emphasis on efficiency-based measures that employ highly structured and formal procedures to develop and implement strategies diagnostically (Abernethy \& Lillis 1995, Bhimani \& LangfieldSmith 2007, Kapu Arachchilage \& Smith 2013).

Furthermore, the prospector strategy does not focus on a manufacturing technology that enables long prediction runs of standardized products using mass production technology and also on achieving cost efficiencies (Miles et al. 1978, Dent 1990). As a result, the prospectors 
Top Manager Orientation, Management Accounting Systems and Strategy Implementation: Evidence from the Sri Lankan Manufacturing Sector

are less focused on traditional accounting information and employee cost techniques so as to focus on task segregation and efficiency measures (Abernethy \& Lillis 1995).

Based on the above the following hypotheses are formed;

H3: Prospector strategy implementation is positively affected by (a) the interactive use of MASs, and (b) the use of innovative MAS information.

H4: Prospector strategy implementation is negatively affected by (a) the diagnostic use of MASs and (b) the use of traditional MAS information.

\section{Technically Oriented Top Managers and Strategy Implementation}

According to UET, the background of top managers has an impact on the selection of strategies in the strategy typology of Miles and Snow (Hambrick \& Mason 1984, Snow and Hrebiniak, 1980, Pavlatos 2012).

The UET literature typically investigates the direct relationship between top manager composition and strategic decisions (Finkelelstein \& Hambrick 1996). Miles et al. (1978) suggested that the organizational leader clearly influences the mode of competition that their firm chooses to adopt and indicated that managers who talk of 'doing things differently' emphasized innovation which is more into 'prospector" strategy, while managers who focused on 'doing things better' emphasized cost control and efficiency which lead to following a 'defender' strategy.

Thomas and Ramaswamy (1996) and Song (1982) have suggested that prospector firms are mostly led by managers with backgrounds in 'output-related functions' such as product, research and development, etc. and are technically oriented.

Top managers with an orientation in science and medicine (technical) were associated with innovation, invention and strategic change (Wiersema \& Bantel 1992, Thomas \& Ramaswamy 1996, Pavlatos 2012), which are core elements of the prospector strategy as they are more focused on 'doing things differently'.

These facts led to the formation of the last hypothesis of the study:

H5: With respect to top managers, a high level of technical orientation is positively related to the implementation of prospector strategy. 
NSBM Journal of Management

Vol. 1, No. 1, January - June, 2015

The overall model containing the hypotheses is depicted in Figure 1.

\section{Figure 1: The Conceptual Framework}

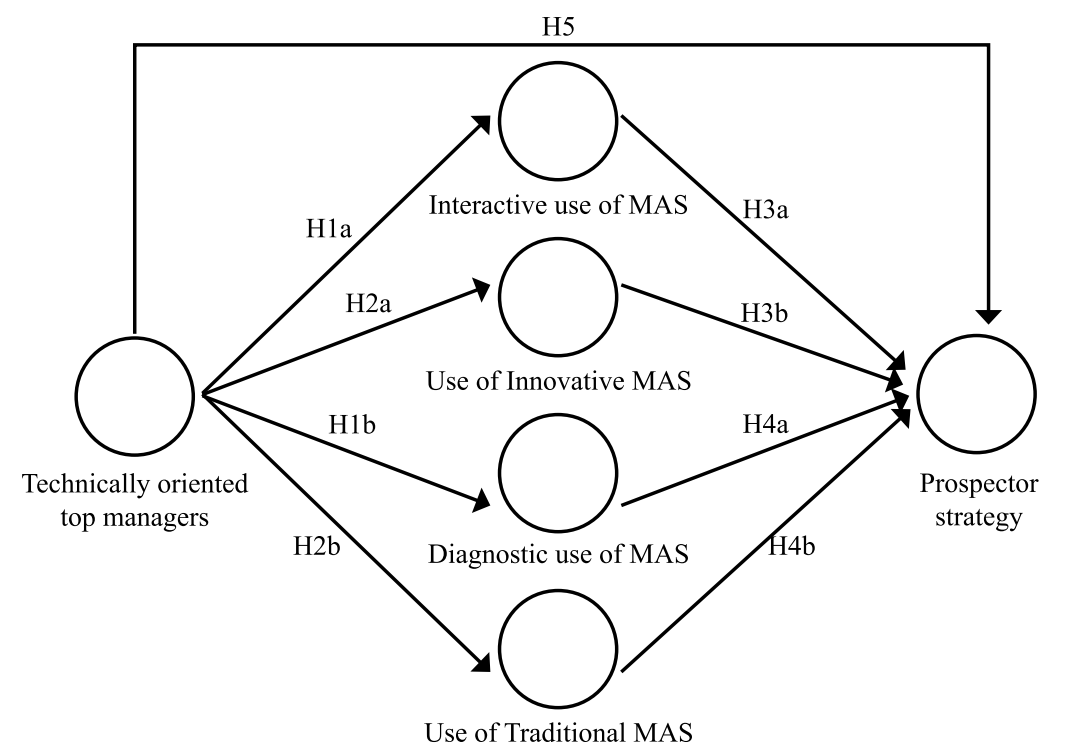

Source: Construction by authors

\section{Methodology}

In order to achieve the objectives of the study, the researchers adopted a quantitative-based approach. To further enrich the findings, the researchers conducted a few in-depth interviews as well so that the findings and implications of the study could be better explained and understood.

\section{Sample Selection}

To study the impact of top managers, the authors selected a sample consisting of managers with technical orientation who make use of MASs for strategy implementation in the manufacturing sector in Sri Lanka.

The manufacturing sector was selected for three main reasons. Firstly, the researchers decided to focus on a single industry, controlling for variables of no theoretical interest to the study, and thus attempting to reduce noise in measurement and analyses (Naranjo-Gil \& Hartmann 2006, Finkelstein \& Hambrick 1996, Bantel \& Jackson1989). Further, focusing on a single 
industry is recommended by Hambrick and Mason (1984) for testing UET. Secondly, the manufacturing sector uses most of the well-known management accounting practices and it is the manufacturing sector that has given birth to most of the management accounting techniques that are being used today (Johnson \& Kaplan 1991). This provides a better setting to observe the use of a variety of well-known management accounting practices. Thirdly, the manufacturing sector in Sri Lanka is currently faced with stiff market competition and change (Kapu Arachchilage \& Smith 2013), which demands organizations to pursue clear strategic goals to simultaneously enhance cost efficiency and flexibility. Thus, the authors focused on the manufacturing sector in Sri Lanka to test and achieve the research objectives of the study.

The selection of top managers for the study was based on the organizational strategic apex, including top management and managers who directly report to the top management (D’Aveni \& Macmillan 1990).Initially the data was collected from 180 respondents in the Sri Lankan manufacturing industry through a written questionnaire which is obtainable from the authors on request.

Thereafter, based on the administrative score developed, the top managers were classified into technical-oriented and administration-oriented (Bantel \& Jackson 1989,Naranjo - Gil and Hartmann 2006, 2007, Naranjo-Gil et al. 2009). Accordingly, of 180 respondents 86 respondents were classified as technical-oriented top managers. The analysis of the study was done using the information collected from 86 technical-oriented top managers.

\section{Data Analysis Approach}

The collected data was subjected to a cleaning process. The data set was analyzed applying Partial Least Squares (PLS) using the SmartPLS software2.0 (M3 release).The final questionnaire prepared after the pre-testing had three main sections: top manager background, use of MASs, and strategy implementation. Each construct was measured as follows using the questionnaire.

The top manager orientation was measured using factual questions relating to top managers' years of educational and functional experience in the technical (professional) field and the administrative (general management) field (Bantel \& Jackson 1989, Naranjo- Gil \& Hartmann 2006, 2007,Naranjo-Gil et al. 2009). Using the information relating to top manager education and experience, an ordinal variable, a ratio of top manager orientation, was developed. The ratio was calculated as the individual administrative years of education and experience of top 


\section{NSBM Journal of Management}

Vol. 1, No. 1, January - June, 2015

managers to the individual total number of years of educational and experience, both technical and administration. Based on the score obtained, the top managers were classified into top managers with technical orientation and top managers with administration orientation. That is, if the score is between $0-0.5$, the orientation of the top manager is regarded as 'technical' and if the score is within $0.5-1$, the orientation of the top manager is regarded as 'administrative.'

Use of MASs was defined in two ways: style of use of MASs and innovative use of MASs. The style was tested by the extent the managers use MASs interactively or diagnostically for their decision making using the concept of 'levers of controls' introduced by Simons (1995). The innovative use of MASs was measured in terms of use of innovative MAS information and use of traditional MAS information.

The top managers' use of MASs, whether it is more interactive or diagnostic, was measured using a five point Likert-type instrument developed by Abernethy and Brownell (1999) and Naranjo- Gil and Hartmann (2006). The instrument was adapted to suit the Sri Lankan manufacturing sector.

The second characteristic of MASs measured was the tendency to use traditional MAS information and innovative MAS information. This was measured using instruments developed by Naranjo-Gil et al. (2009) and Fonseka et al. (2005). The respondents were asked to rate on a five-point Likert type instrument. Strategy implementation by top managers was measured using paragraph descriptions to explain the defender and prospector strategies which are the two extremes of the strategy typology introduced by Miles et al. (1978).

The hypotheses developed were tested using Partial Least Squares (PLS). The use of PLS for the study is relevant for several reasons. Firstly, the researchers' prime objective was prediction-oriented, that is, to explore the impact or the relationship between the top managers' educational and functional experience and their use of MASs and strategy implementation, which PLS can better cater to (Chengalur-Smith, Duchessi \& Gil-Garcia 2012). Secondly, this study is the first study to be conducted in Sri Lanka regarding top managers' orientation, their use of MASs and strategy implementation. Thus, it is in the early stages of theory building and testing, in which scenario many researchers have recommended the use of PLS analysis (Hair et al. 2011, Vinzi et al. 2010, Jayakody 2011). Next, as explained earlier, the data collected for the study is of a non-normal nature and also it is small in sample size which is about 86 (Chengalur-Smith et al. 2012, Hair et al. 2011). Further, the proposed model of the study involved a relatively large number of indicators, constructs and complex relationships 
Top Manager Orientation, Management Accounting Systems and Strategy Implementation: Evidence from the Sri Lankan Manufacturing Sector

where PLS analysis is recommended (Vinzi et al 2010, Jayakody 2011).Therefore, based on the above reasons, the use of PLS for the study was justified.

\section{Data Analysis}

The data analysis firstly describes the profile of the sample and descriptive data. Secondly, the data is cleaned and checked for validity and reliability. Thirdly, the data is presented and analyzed to study the impact of technically oriented top managers in the use of MASs and strategy implementation with a view to meeting the objectives of the study.

Table 1: Top Managers' Composition

\begin{tabular}{llccc}
\hline & & Frequency & Percent & $\begin{array}{c}\text { Cumulative } \\
\text { Percent }\end{array}$ \\
\hline \multirow{2}{*}{ Top manager } & Technical orientation & 86 & 42.7 & 42.7 \\
& Administration orientation & 104 & 57.3 & 100.0 \\
\cline { 2 - 4 } & Total & $\mathbf{1 8 0}$ & $\mathbf{1 0 0 . 0}$ & \\
\hline
\end{tabular}

Source: Compiled by authors based on the survey data

Of the 180 top managers from whom the data was collected only 86 were classified as top managers with a technical background. The data collected from the top managers in the manufacturing industry from different sectors in the field was analyzed further. Table 2 presents the information about the different sectors in which the respondents operate.

Table 2: Sector-wise Classification of Top Managers

\begin{tabular}{lcc}
\hline Sector & No. of Respondents & $\mathbf{\%}$ \\
\hline Apparel & 8 & 9 \\
Ceramic related products & 15 & 17 \\
Construction and Bitumix products & 6 & 7 \\
Electricals & 5 & 6 \\
FMCG & 28 & 33 \\
Other & 6 & 7 \\
Packing Materials, Merbok Doors & 7 & 8 \\
Paints, Charcoal and Batteries & 5 & 6 \\
Rubber related products & 6 & 7 \\
& $\mathbf{8 6}$ & $\mathbf{1 0 0}$ \\
\hline
\end{tabular}

Source: Compiled by authors based on the survey data 
NSBM Journal of Management

Vol. 1, No. 1, January - June, 2015

As Table 2 shows, most respondents are from the Fast Moving Consumer Goods (FMCG), Ceramic products and Apparel sectors.

Table 3: Number of Employees

\begin{tabular}{lccc}
\hline Number of Employees & No. of Organizations & Cumulative Value & \% \\
\hline 100 or less & 8 & 8 & 9 \\
$100-499$ & 45 & 53 & 62 \\
$500-999$ & 19 & 72 & 84 \\
$1000-2999$ & 10 & 82 & 95 \\
$3000-4999$ & 2 & 84 & 98 \\
5000 or more & 2 & 86 & 100 \\
\hline
\end{tabular}

Source: Compiled by authors based on survey data

In Table 3, the employees of the organizations to which the respondents are attached are classified so as to give an indication of the size of the organizations the respondents represent. As the Table shows, most of the respondents (75\%) are from organizations with employees numbering 101-1,000.

\section{Validity and Reliability of the Model}

As is well known, each Structural Equation Model is composed of two sub-models: the measurement model and the structural model. In the measurement model the focus is on establishing the validity and reliability of the measures used to represent each construct of the measurement model (Hair et al. 2011,Vinzi et al.2010, Jung, Wu, \& Chow 2008).

Accordingly, the content validity of the indicators was measured based on the results of the indicator reliability test (Vinzi et al. 2010). Based on the results obtained the lower factor loading variables were eliminated and the rest of the variables was used for further analysis (Abhayakoon \& Balathasan 2013, Hair et al. 2011, Jung et al. 2008).

The construct reliability, convergent validity and the discriminant validity of the measurement model were ensured as follows.

To ensure the construct reliability, the composite reliability and Cronbach's Alpha was used (Chengalur-Smith et al. 2012, Hair et al. 2011,Vinzi et al. 2010). A common measure to examine convergent validity is known as Average Variance Extracted (AVE) (Vinzi et 
Top Manager Orientation, Management Accounting Systems and Strategy Implementation: Evidence from the Sri Lankan Manufacturing Sector

al., 2010).The discriminant validity of the measurement model was used to ensure that a construct is more strongly related to its own measures than in any other construct (Vinzi et al. 2010). For this, the square roots of the Average Variance Extracted (AVE) were compared with the correlations among constructs. Further, factor cross loadings and their correlations were used to measure the discriminant validity of the measurement model indicators (Chengalur-Smith et al. 2012, Hair et al. 2011, Vinzi et al. 2010).

Table 4 presents the information relating to the composite scale reliability, Cronbach's Alpha and AVE measure for each construct of the measurement model.

Table 4: Reliability and Convergent Validity of Constructs

\begin{tabular}{lccc}
\hline & AVE & Composite Reliability & Cronbach's Alpha \\
\hline Diagnostic & 0.6239 & 0.8687 & 0.8069 \\
Innovative & 0.5857 & 0.8489 & 0.7645 \\
Interactive & 0.5912 & 0.8516 & 0.7718 \\
No. EMP & 1 & 1 & 1 \\
Prospector & 1 & 1 & 1 \\
Tech & 1 & 1 & 1 \\
Traditional & 0.7399 & 0.8948 & 0.8227 \\
\hline
\end{tabular}

Source: Compiled by authors based on survey data

Table 5: Inter-Construct Correlations

\begin{tabular}{llllllll}
\hline & Diagnostic & Innovative & Interactive & No. EMP & Prospector & Tech & Traditional \\
\hline Diagnostic & 0.6239 & & & & & & \\
Innovative & -0.1084 & 0.5857 & & & & & \\
Interactive & 0.0373 & 0.5965 & 0.5912 & & & \\
No. EMP & 0.1295 & 0.2699 & 0.2742 & 1.000 & & & \\
Prospector & -0.3197 & 0.4574 & 0.3948 & 0.0064 & 1.000 & & \\
Tech & -0.3718 & 0.2831 & 0.1835 & -0.1595 & 0.5334 & 1.000 & 0.7399 \\
Traditional & 0.4729 & 0.1137 & 0.1153 & 0.1595 & -0.1907 & 0.3675 & \\
\hline
\end{tabular}

* Note: Square root of AVE is given in the diagonal

Source: Compiled by authors compiled based on the SmartPLS output 
NSBM Journal of Management

Vol. 1, No. 1, January - June, 2015

Table 6: Cross Loadings for the Measurement Model

\begin{tabular}{llllllll}
\hline & Diagnostic & Innovative & Interactive & No. EMP & Prospector & Tech & Traditional \\
\hline @2_1_10D & 0.7752 & -0.0257 & -0.0108 & 0.0836 & -0.1716 & -0.2418 & 0.336 \\
@2_1_12I & 0.2443 & 0.4546 & 0.6769 & 0.2182 & 0.1436 & 0.0188 & 0.2243 \\
@2_1_13I & 0.0292 & 0.5362 & 0.863 & 0.2114 & 0.3675 & 0.2099 & 0.0657 \\
@2_1_14I & -0.1387 & 0.4566 & 0.7833 & 0.2516 & 0.2447 & 0.198 & 0.0369 \\
@2_1_1D & 0.8517 & -0.1566 & -0.015 & 0.1086 & -0.3118 & -0.441 & 0.4738 \\
@2_1_4D & 0.8004 & -0.0863 & 0.0129 & 0.1268 & -0.2932 & -0.2203 & 0.3611 \\
@2_1_5I & 0.0694 & 0.3991 & 0.7405 & 0.1778 & 0.3933 & 0.0847 & 0.0927 \\
@2_1_7D & 0.7272 & -0.0133 & 0.1938 & 0.0841 & -0.1855 & -0.1754 & 0.2565 \\
@2_4_10I & 0.0132 & 0.6622 & 0.4179 & 0.2166 & 0.2137 & 0.1337 & 0.1418 \\
@2_4_14T & 0.4519 & 0.0873 & 0.0399 & 0.1031 & -0.2543 & -0.3296 & 0.9021 \\
@2_4_15T & 0.3619 & 0.0044 & 0.1035 & 0.1253 & -0.0955 & -0.3162 & 0.8831 \\
@2_4_16T & 0.3976 & 0.1997 & 0.1648 & 0.1889 & -0.124 & -0.3009 & 0.7912 \\
@2_4_1I & -0.1853 & 0.765 & 0.4583 & 0.2159 & 0.4324 & 0.2058 & -0.0291 \\
@2_4_3I & -0.099 & 0.8174 & 0.5387 & 0.1473 & 0.3596 & 0.2422 & 0.054 \\
@2_4_7I & -0.0287 & 0.8067 & 0.4192 & 0.2488 & 0.3551 & 0.2643 & 0.2016 \\
B & -0.3197 & 0.4574 & 0.3948 & 0.0064 & 1 & 0.5334 & -0.1907 \\
No._Emp & 0.1295 & 0.2699 & 0.2742 & 1 & 0.0064 & -0.1595 & 0.1595 \\
Tech & -0.3718 & 0.2831 & 0.1835 & -0.1595 & 0.5334 & 1 & -0.3675 \\
\hline
\end{tabular}

Source: Compiled by authors based on survey data

According to Table 4, the composite reliability and Cronbach's Alpha are well above 0.7 , which suggests the construct reliability of the measurement model indicators. Furthermore, all the indicators have achieved an AVE value of well above 0.5 , which ensures the convergent validity (Hair et al. 2011,Vinzi et al. 2010).

The discriminant validity which is well supported by the results of the inter-construct correlations and cross loadings is presented in Tables 5 and 6 respectively. In Table 4 the square root of AVE represented in the diagonal is higher than its column-wise and row-wise correlation values, which suggests a strong discriminant validity of measures, and this is well supported by the cross loadings which is evident in the loadings of the constructs that are higher than the loadings of the particular measure which is used for other constructs.

Hence, the first step of the PLS analysis, which is about establishing the measurement model validity and reliability, is completed and the results obtained, and the reliability and validity of the model are ensured. 
Top Manager Orientation, Management Accounting Systems and Strategy Implementation: Evidence from the Sri Lankan Manufacturing Sector

\section{The Structural Model}

PLS provides three estimates to assess the structural model or the relationship between latent variables: path coefficient, corresponding significant score, and the coefficient determinant. The path coefficient is similar to the beta value of the traditional regression model. The significant score is determined using the t-value generated through the bootstrapping procedure in PLS. The coefficient of determination indicates the overall effect size and can be used to examine the degree of variance of the dependent variable, which is explained by the independent variables ( Vinzi et al. 2010, Jayakody 2011).

The bootstrapping procedure was performed using 5,000 samples, where the use of individual sign changes was used as a sign change option (Hair et al. 2011,Vinzi et al. 2010, Jung et al. 2008) and the results of the structural model are depicted in Figure 2 and Table 7. The number of organizational employees was used in the model as the controlling variable to control the effects of organizational size.

Figure 2: Results of the Structural Model with Path Coefficients

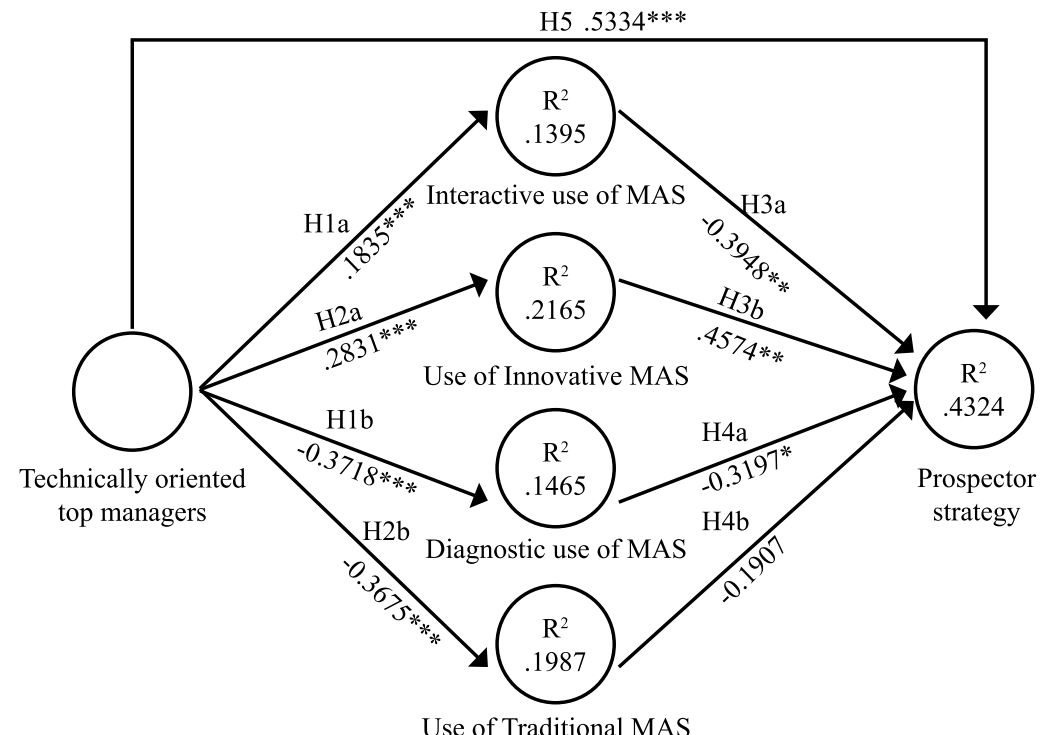

Source: Compiled by authors based on the SmartPLS output

Organizational size was measured by the number of employees in the organization and the results suggest that there is a significant impact on the interactive use of MASs and innovative use of MASs and it does not have any influential impact on strategy implementation. 


\section{NSBM Journal of Management}

Vol. 1, No. 1, January - June, 2015

The results in Table 7 support the expected positive relationship between technically oriented top managers and the interactive use of MASs (H1a). The expected negative relationship between technically oriented top managers and the diagnostic use of MASs (H1b) is also confirmed. Support was also found for the expected relationships between technically oriented top managers and the use of innovative MAS information and use of traditional MAS information (H2a and $\mathrm{H} 2 \mathrm{~b}$ ).

In the PLS analysis the researchers included a control variable with paths to all dependent variables. The results obtained are those of the model tested with the control variable. For reasons of clarity, the controlling variable is not included in the graphical presentation.

Regarding the relationships between the use of MASs and strategy implementation, Table 5 shows the support for $\mathrm{H} 3 \mathrm{a}$ and $\mathrm{H} 3 \mathrm{~b}$, which suggest that the use of MASs interactively and the use of innovative MAS information facilitates the implementation of prospector strategy. The results of the data analysis support H4a but do not support H4b. This suggests that the diagnostic use of MASs is negatively related to the implementation of prospector strategy while the negative relationship of use of traditional MASs has no significant impact, as the results show.

The relationship expected between the technically oriented top managers and prospector strategy implementation is also confirmed by the results obtained. 
Top Manager Orientation, Management Accounting Systems and Strategy Implementation: Evidence from the Sri Lankan Manufacturing Sector

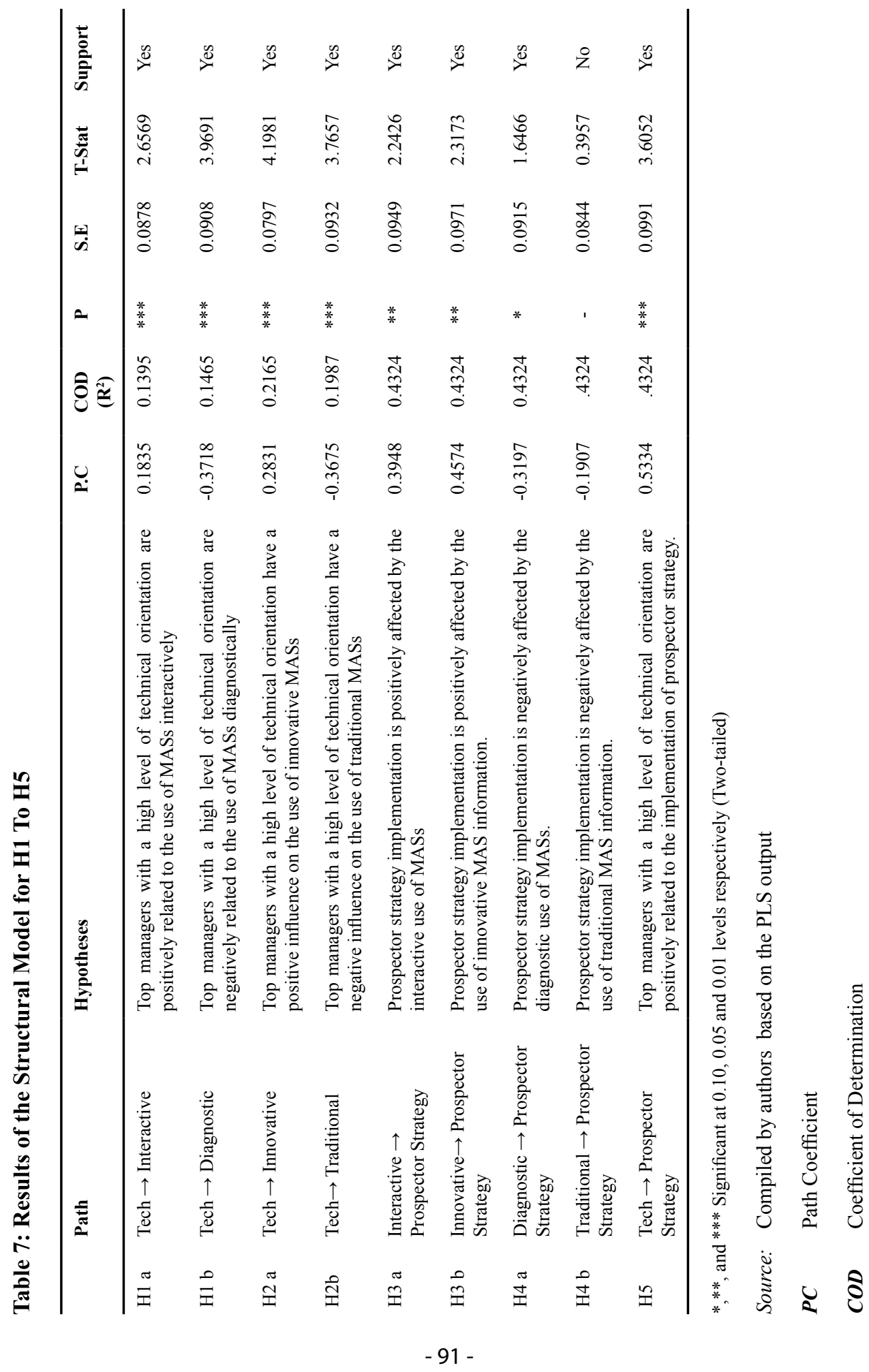


NSBM Journal of Management

Vol. 1, No. 1, January - June, 2015

\section{Discussion}

The study explored how technically oriented top managers in Sri Lanka use MASs differently and how MASs support the strategy implementation process and the impact of technically oriented top managers on strategy implementation.

\section{Top Manager Orientation and Use of MASs}

The results obtained suggest that top manager orientation affects the use of MASs and such use affects strategy implementation. Top managers who are more technically oriented use MASs more interactively and less diagnostically.

Technically oriented top managers with their educational orientation are believed to possess less understanding of MASs and related performance measures and are more interested and knowledgeable about the primary process of the organization (Naranjo-Gil \& Hartmann 2006, 2007). On the other hand, technically oriented top managers with their education and experience of technical functionalities have a very strong knowledge of the products and production process of the organization and as a result, as suggested by Østergren (2009), technically oriented top managers tend to use MASs mostly in an interactive way and use MASs mostly as a communication tool to come up with consensus solutions for the organization as a whole. For the above reasons, top managers with a technical orientation differ in interpreting the information generated via MASs, where they define the information largely in terms of activities and goals relating to their field of expertise. These findings are consistent with the findings of Østergren, (2009), Naranjo-Gil and Hartmann (2007),Hartmann (2005), Armstrong (1987) and Hambrick and Mason (1984).

Because of the wide knowledge the technically oriented top managers have of production and the production process of the organization, they allow more autonomy for their subordinates and also encourage employee participation in the decision making process. This leads to a bottom-up approach to decision making which is supported by the findings of Abernethy and Stoelwinder (1990), Armstrong (1987) and Naranjo-Gil and Hartmann (2006, 2007). On the other hand, as technically oriented top managers are competent and comfortable in handling and understanding the core operating tasks of the organization, as suggested by Ittner and Larcker (1995), they encourage the bottom-up process of information in the process of problem solving which demands the attention of all levels of managers, peers and subordinates and encourage organizational attention from all levels of managers. These findings are in line with the conclusions of Chenhall et al. (2011), Naranjo-Gil and Hartmann (2006, 2007), Schäffer and Steiners (2004) and Simons (1995). As discussed earlier, technically oriented 
top managers do not possess a strong accounting-based knowledge. They only learn and get more insights into the relevant accounting terms and their importance during the management discussions in the organization. Thus, they use these terms and information to create and continue a dialogue with administratively-oriented top managers and therefore, as suggested by Abernethy and Vagnoni, (2004), they use MASs to cope with role conflict and to improve communication and dialogue with their professional peers.

During the interviews a General Manager of a leading ceramic tile organization in Sri Lanka, who has a technical orientation, described how he used the MAS in his organization.

... The information that MAS provides is very important to us and it's our management accountant who takes care of our whole accounting system and he is the one who takes care of preparing and interpreting the relevant management accounting information. I listen to him and do the needful as per his suggestions, after discussing the facts with other top managers as well....

This again confirms that technically-oriented top managers use MASs as a way of organizational learning, coordination and communication, which are integral components of interactive controlling systems suggested by Simons (1995).

The results obtained further suggested that technically-oriented top managers use more of innovative MAS information than traditional MAS information. As discussed earlier, technically-oriented top managers encourage organizational learning and innovation (Abernethy \& Vagnoni 2004). In order to better facilitate innovation and organizational learning, top managers with a technical orientation need various kinds of strategic information which is better provided through innovative use of MASs. Thus it helps the said managers in managing and improving the organizational performance (Chenhall et al. 2011, Pavlatos 2012). Further, the innovative MAS information encourages innovation and thus helps the organization to be more proactive.

During the interviews a technically-oriented general manager emphasized using innovative management accounting information as follows:

... To maintain the quality of our products and to encourage the innovations, we practice lot of new management accounting practices such as Kaizan, Lean, Quality circles and also we are an ISO certified company... 


\section{NSBM Journal of Management}

Vol. 1, No. 1, January - June, 2015

Therefore, the interviews carried out and the statistical analyses indicate that technically oriented top managers use innovative MAS information.

On the other hand, technically-oriented top managers pay minimum attention to obtain information on operational efficiencies, cost minimization, meeting targets, etc. Hence they are less likely to use MASs more conservatively which is the case in using traditional MASs. Therefore, technically- oriented top managers are negatively related to the use of traditional MAS information.

\section{Use of MASs and Strategy Implementation}

H3a of the study hypothesized that there is a positive relationship between the interactive use of MASs and prospector strategy implementation.

Miles et al. (1978) categorized prospector strategy as dynamism in seeking new market opportunities and capabilities to develop new products to find creative new responses to suit customer demands. According to (Maher, 2000), the interactive use of MASs adds elements needed to respond appropriately and profitably to today's markets and to respond to the demands of flexibility, innovation and creativity which are the core elements of prospector strategy. Such use of MASs will harness the creativity that often leads to new product line extensions, processes and markets, and also enable managers to involve themselves regularly and personally in the decisions of subordinates.

Abernethy and Lillis (1995) suggested that a firm's ability to respond to market demands increases through coordinated policies and actions and willingness or capacity to offer product variations. The use of MASs interactively facilitates communication and coordination and therefore manufacturing flexibility.

The core elements of the interactive use of MASs, which facilitate manufacturing flexibility, inter-functional coordination and adaptation, have helped organizations to implement prospector strategy successfully and thus, the implementation of prospector strategy is enhanced by the use of MASs interactively. As prospector strategy encourages the interactive use of MASs it discourages the use of diagnostic MASs. This is indicated in Hypothesis H4a which depicts a negative significant relationship between the diagnostic use of MASs and prospector strategy implementation. Prospector organizations do not focus on improving the efficiency of their existing operations, are inflexible but cost efficient, and have highly 
structured formal controls. This finding is consistent with the conclusions of Naranjo-Gil et al. (2009) and Abernethy and Lillis (1995).

$\mathrm{H} 3 \mathrm{~b}$ confirmed the positive relationship predicted between the innovative use of MASs and prospector strategy implementation. This finding is consistent with the prior works of Naranjo-Gil and Hartmann (2009), Maher (2000) and Miles et al. (1978).

As discussed, prospector strategy emphasizes innovation, flexibility, manufacturing strategies, and exploring new markets. Therefore, prospector strategy encourages product differentiation. Chenhall and Langfield-Smith (1998) found that innovative MASs are used more in the strategies that give more emphasis to product differentiation. Also, Bouwens and Abernethy (2000) showed that firms that produced highly customized products are more likely to adopt broad scope MASs which includes the use of more innovative MASs. This is because when organizations follow strategies based on innovativeness like prospector strategy, traditional based MASs alone will not be adequate for decision making to competitively engage in business and to survive. Further, prospectors operate in a highly dynamic environment which involves frequent changes and quick responses to new market opportunities. Innovative MAS techniques can better cater to such dynamic changes. Innovative MASs provide more futuristic information which is more important in a dynamic environment (Drury 2010).

In the interviews a General Manager of a prospector strategy implemented organization stated:

...Employees are highly encouraged to come up with their innovative ideas that can improve the operations of our organization. So we encourage the practice of Kaizen. Also to ensure the quality of our products TQM is implemented. Value chain analysis is also helpful in being efficient and managing the supply chain operations of the organization well...

The statement also supports the findings of the data analysis and therefore it can be concluded that the use of innovative MASs have a strong impact on the adoption of prospector strategy implementation.

H4b of the study predicted a negative relationship between the traditional use of MASs and the implementation of prospector strategy. Even though the results obtained revealed a negative relationship it was not statistically significant. Naranjo-Gil et al. (2009) have argued that it is common to use traditional MASs in every organization irrespective of the strategy they implement because of the importance of the information provided by traditional MASs. 
NSBM Journal of Management

Vol. 1, No. 1, January - June, 2015

Therefore the relationship proposed between the traditional use of MASs and prospector strategy implementation is not accepted in the study.

\section{Top Manager Orientation and Strategy Implementation}

Miles et al. (1978) described prospector strategy as companies that use innovativeness as the cornerstone of competitive advantage, where they offer a large array of state of the art products that are targeted at a variety of market segments. The results of H5 of the study confirmed a strong positive relationship between technically-oriented top managers and implementation of prospector strategy.

Innovativeness and the search for new market opportunities are well supported by the technically oriented top managers as they provide more autonomy and encouragement to their employees so that they have more freedom to think differently and come up with new products, market segments and production techniques, etc.

Further, technically oriented top managers are said to better face strategic change (Naranjo-Gil et al. 2009, Abernethy \& Brownell 1999). To cope with change and competition, technically oriented top managers with their knowledge and experience of production process and techniques use their knowledge to make innovations. They look for various input substitutes which provide better quality either at the same cost or at reduced cost, add new features to the products or look for new market opportunities (Pavlatos 2012, Thomas \& Ramaswamy 1996,Wisersema \& Bantel 1992). These characteristics embedded in technically-oriented top managers match the core elements of the prospector strategy identified by Miles et al. (1978).

In the interviews this was supported by a managing director who is a technically oriented top manager in a leading Sri Lankan paint manufacturing company. He stated:

... When I do new additions to my products or to my businesses, I always go for the latest technology based innovations..., I'm so interested in studying and using new technology and new production methods... they provide us the competitive advantage to prosper in the future...

Therefore, the interviews and the statistical analysis confirm that the technically-oriented top managers go for technology-based developments and innovations and they encourage the implementation of prospector strategy. 
Top Manager Orientation, Management Accounting Systems and Strategy Implementation: Evidence from the Sri Lankan Manufacturing Sector

\section{Managerial and Practical Implications}

The findings of the study are in line with the findings of Hambrick and Mason's (1984) Upper Echelon Theory (UET) and therefore, the current study confirms the applicability of UET in the Sri Lankan manufacturing sector. The study also provided insights into the links between uses of MASs and Miles et al. (1978) strategy typology. Accordingly, it was revealed that the interactive use of MASs and use of innovative MAS information assists the implementation of prospector strategy while the use of MASs diagnostically does not support the implementation of prospector strategy.

The findings benefit the business organizations in Sri Lanka in building the composition of top manager teams to match their strategy. Therefore, they will aid organizations to adopt and evolve in competitive dynamic business environments, especially at a time where the diverse composition of top management teams is on the rise and such top manager composition changes will have an impact on the firm's performance (Carson, Mosley \& Boyar 2004).

The study further emphasized the importance of management accounting in providing information to match organizational strategy implementation. Organizations adopting the prospector strategy emphasize competitor position and information, and product market moves and information (Bhimani \& Langfield-Smith 2007). Such information requirements are better met through the interactive style of use of MASs and use of innovative MAS information. The interactive style of use of MASs will help organizations to improve the organizational communication, team work, information sharing, etc. which facilitate innovation and establishing new horizons for the business.

The results of the study should help the top management of an organization to gain a better understanding of the potential uses of MASs for improving organizational performance, mainly relating to different uses of MASs and its impact on strategy implementation. Thus, they can better adjust the use of MASs to suit the specific style of strategy implementation (Anthony \& Govindarajan 2004, Schäffer \& Steiners 2004).

Technically oriented top managers are more focused on doing things differently that lead them to prefer the implementation of prospector strategy. Further, they are more willing to use MASs interactively which enhances organizational communication and information flow. The technically oriented top managers also prefer to use innovative MAS information which facilitates the innovative organizational culture. Thus, it can be concluded that the orientation of the top manager has a profound impact on the use of MASs and strategy. 
NSBM Journal of Management

Vol. 1, No. 1, January - June, 2015

\section{Directions for Future Research}

The researchers focused only on two observable managerial characteristics out of the six proposed in UET (Hambrick \& Mason 1984). Hence, future researchers can expand their studies to cover other observable characteristics or a combination of them (Hambrick \& Mason 1984, Bantel \& Jackson 1989). In this study, the data was derived at a given point of time and as a result, the direction of significant associations could not be determined and therefore longitudinal studies on this area of study are encouraged. The sample for the study was collected from the Sri Lankan manufacturing sector. Generalizing the results to other industries or countries should be done carefully (Abernethy \& Brownell 1999). Therefore, further research is required on its applicability in other industries in order to access the generalizability of the model.

\section{Conclusion}

The study suggests that top managers with a high level of technical orientation are more innovative and willing to do things differently. This drives them to support prospector strategy implementation. Further, such managers use MASs more interactively as they use MASs for communication, coordination, motivation, and as a learning machine in managing their organizations. Since the technically oriented top managers do not possess a sound understanding of financial controls and measures, they are less likely to use MASs diagnostically. The nature of innovativeness and exploring new market opportunities by the technically oriented top managers drives the need for different financial and non-financial information for decision making. As a result, technically oriented managers use more of innovative MAS information than the traditional MAS information.

The study also suggests that the diagnostic use of MASs will not facilitate the adoption of prospector strategy. Further, the interactive use of MASs and use of innovative MAS information aid the implementation of prospector strategy. This is because the use of MASs interactively will allow organizational learning and communication to support innovations. Also, the use of innovative MAS information will generate various financial and non-financial information which leads to create different competitive advantages for the organizations that will also help them to grow and survive in a competitive and dynamic business environment of today. 


\section{References}

Abernethy, MA \& Brownell, P 1999, 'The role of budgets in organizations facing strategic change: an exploratory study', Accounting, Organizations and Society, vol. 24, no. 3, pp.189-204.

Abernethy, MA \& Lillis, AM 1995, 'The impact of manufacturing flexibility on management control system design', Accounting, Organizations and Society, vol. 20, no.4, pp.241-258.

Abernethy, MA \& Stoelwinder, JU 1990, 'The relationship between organization structure and management control in hospitals: an elaboration and test of Mintzberg's professional bureaucracy model', Accounting, Auditing and Accountability Journal, vol. 3, no.3.

Abernethy, MA \& Vagnoni, E 2004, 'Power, organization design and managerial behavior', Accounting, Organizations and Society, vol. 29, no. 3-4, pp. 207-225.

Abhayakoon, PGIDW \& Balathasan, Y 2013, 'Transformational leadership and organizational innovation in selected Sri Lankan industries'. Unpublished Master's dissertation, Postgraduate Institute of Management, University of Sri Jayewardenepura, Sri Lanka.

Armstrong, P 1987, 'Engineers, Management and Trust', Work, Employment \& Society, vol. 1, no. 4, pp.421-440.

Bantel, KA \& Jackson, SE 1989, 'Top management and innovations in banking: does the composition of the top team make a difference?', Strategic Management Journal, vol. 10. no. S1, pp.107-124.

Baysinger, B \& Hoskisson, RE 1990, 'The composition of boards of directors and strategic control: effects on corporate strategy', Academy of Management Review, vol. 15, no.1, pp.72-87.

Bhimani, A \& Langfield-Smith, K 2007, 'Structure, formality and the importance of financial and non-financial information in strategy development and implementation'. Management Accounting Research, vol.18, no. 1, pp.3-31.

Bouwens, J \& Abernethy, MA 2000, 'The consequences of customization on management accounting system design', Accounting, Organizations and Society, vol. 25, no.3, pp.221-241.

Brownell, P \& Merchant K 1990, 'The budgetary and performance influences of product standardization and manufacturing process automation', Journal of Accounting Research, vol. 28, no.2, pp.388-397.

Carpenter, MA, Geletkanycz, MA\& Sanders, WG 2004, 'Upper echelons research revisited: antecedents, elements, and consequences of top management team composition'. Journal of Management, vol. 30, no. 6 , pp.749-778.

Carson, CM, Mosley, DC \& Boyar, SL 2004, 'Performance gains through diverse top management teams', Team Performance Management, vol.10, no.5/6, pp.121-126.

Chengalur-Smith,I, Duchessi, P \& Gil-Garcia, JR 2012, 'Information sharing and business systems leveraging in supply chains: an empirical investigation of one web-based application'. Information and Management, vol. 49, no. 1, pp.58-67.

Chenhall, RH \& Langfield-Smith, K 1998, 'The relationship between strategic priorities, management techniques and management accounting: an empirical investigation using a systems approach', Accounting, Organizations and Society, vol.23, no.3, pp.243-264. 


\section{NSBM Journal of Management}

Vol. 1, No. 1, January - June, 2015

Chenhall, RH, Kallunki, JP \& Silvola, H 2011, 'Exploring the relationships between strategy, innovation, and management control systems: the roles of social networking, organic innovative culture, and formal controls', Journal of Management Accounting Research, vol. 23, no.1, pp.99-128.

D'Aveni, RA \& MacMillan, IC 1990, 'Crisis and the content of managerial communications: a study of the focus of attention of top managers in surviving and failing firms', Administrative Science Quarterly, vol.20, pp.634-657.

Dent, JF 1990, 'Strategy, organization and control: some possibilities for accounting research', Accounting Organizations and Society, vol.15,no.1, pp.3-25.

Drury, C 2010, Management and cost accounting. Cengage Learning EMEA.

Finkelstein, S \& Hambrick, DC 1996, Strategic Leadership: top Executives and their Effects on Organizations, West Publishing Company, St.Paul, Minneapolis.

Fonseka, KBM, Manawaduge, ASPG \& Senarathne, DSNP 2005, Management Accounting practices in quoted public companies in Sri Lanka”, CIMA Sri Lanka division, Colombo.

Gaidienë, Z \& Skyrius, R 2006, 'The usefulness of management accounting information: users' attitudes', Ekonomika, vol.74, pp.21-37.

Galbraith, JR 1973, Designing complex organizations, Addison-Wesley Longman Publishing Co., Inc.

Hair, JF, Sarstedt, M, Ringle, CM \& Mena, JA 2011, 'An assessment of the use on partial least squares structural equation modeling in marketing research', Journal of the Academy of Marketing Science, vol.40, no.3, pp.414-433.

Hambrick, DC 2007, 'Upper echelons theory: an update', Academy of Management Review, vol. 32, no. 2, pp.334-343.

Hambrick, DC \& Mason, PA 1984, 'Upper echelons: the organization as a reflection of its top manager', The Academy of Management Review, vol. 9, no. 2, pp.193-206.

Hartmann, F 2005, 'The effects of tolerance for ambiguity and uncertainty on the appropriateness of accounting performance measures', Abacus, vol. 41, no.3, pp.241-264.

Hayes, D. 1977, 'The contingency theory of managerial accounting', The Accounting Review, vol.1, pp.23-39.

Hitt, MA \& Tyler, BB 1991, 'Strategic decision models: integrating different perspectives', Strategic management Journal, vol. 12, no.5, pp.327-351.

Ittner, CD \& Larcker, DF 1995, 'Total quality management and the choice of information and reward systems', Journal of Accounting Research, vol. 33,Supplement, pp.1-34.

Ittner, CD \& Larcker, DF 2001, 'Assessing empirical research in managerial accounting: a value-based management perspective'. Journal of Accounting and Economics, vol.32, pp 349-410.

Jayakody, JASK 2011. 'Effects of leader charisma on follower dependency in Sri Lanka'.An unpublished $\mathrm{PhD}$ thesis, Postgraduate Institute of Management, University of Sri Jayewardenepura, Sri Lanka.

Johnson, HT \& Kaplan, RS 1991, Relevance lost: the rise and fall of management accounting, Harvard Business Press. 
Jung, D, Wu, A \& Chow, CW 2008, 'Towards understanding the direct and indirect effects of CEOs' transformational leadership on firm innovation', The Leadership Quarterly, vol.19, no.5, pp.582-594.

Kaplan, RS \& Norton, DP 1996, 'Using the scorecard as a strategic management system', Harvard Business Review (January - February), pp.75-85.

KapuArachchilage, ND \& Smith, M 2013, 'The effects of the diagnostic and interactive use of management control systems on the strategy-performance relationship", The Journal of Applied Management Accounting Research, vol. 11, no.1.

Langfield-Smith, K 1997, 'Management control systems and strategy: a critical review', Accounting, Organizations and Society, vol. 22, no.2, pp.207-232.

Macintosh, NB 1985, Social software of accounting and information systems, John Wiley \& Sons, Inc.

Maher, MW 2000, 'Management accounting education at the millennium'. Issues in Accounting Education, vol.15, no.2, pp. 335-346.

Miles, RE, Snow, CC, Meyer, AD \& Coleman, HJ 1978, 'Organizational strategy, structure, and process”, Academy of Management Review, vol. 3, no. 3, pp.546-562.

Mintzberg, H 1990, 'The design school: reconsidering the basic premises of strategic management', Strategic Management Journal, vol. 11, no.3, pp.171-195.

Naranjo-Gil, D \& Hartmann, F 2007, 'How CEOs use management information systems for strategy implementation in hospitals', Health Policy, vol. 81, no.1, pp.29-41.

Naranjo-Gil, D \& Hartmann, F 2006, 'How top management teams use management accounting systems to implement strategy', Journal of Management Accounting Research, vol. 18, pp.21-53.

Naranjo-Gil, D, Maas, VS \& Hartmann, FGH 2009, 'How CFOs determine management accounting innovation: an examination of direct and indirect effects', European Accounting Review, vol.18, no.4, pp.667-695.

Nishii, LH, Gotte, A \& Raver, JL 2007, 'Upper echelon theory revisited: the relationship between upper echelon diversity, the adoption of diversity practices, and organizational performance', Center for Advanced Human Resource Studies.

Østergren, K 2009, 'Management control practices and clinician managers: the case of the Norwegian health sector', Financial Accountability and Management, pp.167-195.

Pavlatos, O 2012, 'The impact of CFOs' characteristics and information technology on cost management systems'. Journal of Applied Accounting Research, vol. 13, no. 3, pp.242-254.

Schäffer, U \& Steiners, D 2004, 'The use of management accounting information, learning and organizational performance', European Business School Working Papers on Management Accounting and Control, vol. 11 (revised version).

Simons, R 1995, Control in an age of empowerment', Harvard BusinessPress.

Simons, R 1991, 'Strategic orientation and top management attention to control systems', Strategic Management Journal, vol. 12, no.1, pp.49-62.

Simons, R 2000, 'Performance measurement and control systems for implementing strategy: text \& cases', Prentice Hall, Upper Saddle River, New Jersey. 
NSBM Journal of Management

Vol. 1, No. 1, January - June, 2015

Snow, CC \& Hrebiniak, LG 1980, 'Strategy, distinctive competence, and organizational performance', Administrative Science Quarterly, pp.317-336.

Song, JH (1982), 'Diversification strategies and the experience of top executives of large firms', Strategic Management Journal, vol.3, no.4, pp.377-380.

Sumer, K \& Bayraktar, CA 2012, 'Business strategies and gaps in Porter's typology: aliterature review', Journal of Management Research, vol.4, no.3.

Thomas, AS \& Ramaswamy, K 1996, 'Matching managers to strategy: further tests of the Miles and Snow typology', British Journal of Management, vol.7, no. 3, pp.247-261.

Vinzi, VE, Chin, WW, Henseler, J \& Wang, H 2010, Handbook of partial least squares concepts, methods and applications', Springer, Berlin Heidelberg.

Wiersema, MF \& Bantel, KA 1992, 'Top management team demography and corporate strategic change', Academy of Management Journal, vol.35, no.1, pp.91-121. 